Manual of Histological Techniques. JD Bancroft and HC Cook. (Pp 274; £12.50.) Churchill Livingstone. 1984 .

This is restricted to histological staining methods, mainly dye staining techniques with some enzyme histochemistry and a very little immunocytochemistry. It has a similar format to its more useful companion volume "Theory and Practice of Histological Techniques" by Bancroft and Stevens but is cheaper, smaller, and soft back; it contains much the same staining methods but lacks tissue processing and sectioning as well as all the other wider aspects of histopathological technique. Little has been gained and much has been lost in this return to traditional dye staining methods. This book does not reflect the great advances that have been made in histopathology and trainees should be encouraged to read more widely.

\section{RAB DRURY}

Molecular Basis of Lysosomal Storage Disorders. Ed JA Barranger and RO Brady. (Pp 502; £31·50.) Academic Press Inc. 1984.

This volume is the proceedings of a conference on lysosomal storage diseases which was held at the National Institutes of Health, Bethesda, in September 1983 and in which many of the leading workers in the field took part. It is an excellent summary of the position as it was at that date and although one regrets the time lapse in its appearance, it is still a valuable and topical publication for those interested in lysosomal enzymes and the inborn errors of metabolism which are due to metabolic lesions involving them. Although the first of the activator proteins which are necessary for the activity of lysosomal enzymes was isolated as long as 20 years ago, this subject has advanced rapidly in recent years and there are outstanding contributions on it in this volume. The mechanisms which route lysosomal enzyme proteins to the prelysosomal compartment and away from the pathways followed by secretory glycoproteins are a field in which there was much to report and which offer a basis for a whole new range of inborn errors of metabolism of which I-cell disease (mucolipidosis II) can be considered to be the archetype.

The four chapters on the biosynthesis of lysosomal enzymes with particular reference to hexosaminidase and $\alpha$-glucosidase are particularly welcome.

The section on molecular genetic aspects is important for clinical molecular geneticists because of the valuable accounts of the progress with respect to the cloning of genes for the enzymes, lesions of which are responsible for lysosomal storage diseases. The chapter on strategies for the molecular cloning of low abundance messenger RNAs is particularly important.

The section on treatment deals with bone marrow transplantation in the treatment of lysosomal storage diseases as exemplified by the continuing work on Hurler disease and a report of the use of this approach in a case of Gaucher disease. There is also an account of the present position with respect to enzyme supplementation in Gaucher disease. The position with respect to these subjects is slowly being clarified.

This book is firmly recommended for clinical and laboratory investigators working on the lysosomal storage diseases and the more applied aspects of lysosomal physiology. Other readers, particularly paediatricians and biochemists, will also find much of interest.

RWE WATTS

Hematopoiesis. Methods in Hematology. Ed David W Golde. (Pp 361; £38.) Churchill Livingstone. 1984.

This valuable addition to the "Methods in Hematology" series provides a comprehensive resumé of the methods used for the study of in vivo and in vitro haematopoiesis. One of the problems experienced by new workers in this field is that superficially minor technical aspects crucial to the success of a method are not fully discussed in original publications. This volume will do much to help in this regard, including as it does lists of possible faults, clear instructions for colony recognition, and advice on the preparation of the most mundane ingredients. There is also a short section on the methods for in vitro enrichment of human stem cells, although I suspect this is the one part of the book that will soon be out of date.

This book will not be a substitute for gaining experience in the field but will make the setting up of new methods much easier. Newcomers will find those chapters relevant to their interests essential reading, and the volume will be needed by most laboratories which grow blood cells.

IM FRANKLIN

The Physiology and Pathophysiology of the Skin. Vol 8. The Photobiology of the Skin Lasers and the Skin. Ed A Jarrett. (Pp 2704; £49.) Academic Press. 1984.
This book is the latest in a series which in the previous seven volumes has covered anatomically defined subjects (the epidermis, nerves, and blood vessels, the dermis and dendrocytes, sweat glands, the mucus membranes), and pathophysiological topics (skin permeation, transepidermal water loss, hormonal control of pigmentation, and the biology of melanoma). This volume covers photobiology (187 pages), and lasers (18 pages). The relative lengths of these contributions probably reflect the degree of current use of these two treatment modalities by clinical dermatologists.

The section on the photobiology of the skin is written by Brian Johnson, Senior Lecturer in Photobiology in the Department of Dermatology at the University of Dundee. It is currently commonplace for able and enthusiastic younger workers with medical qualifications to take a "sideways step", spending a year or two in a laboratory learning the scientific techniques of the new biology-gene cloning, monoclonal antibody production, oncogene detection, and the like. It is not common, however, for a scientist to take the time and trouble to become really well versed in the clinical problems related to his research area to such an extent that his knowledge is in many cases greater than that of medical colleagues. Dr Johnson has done just this and his approach is a welcome breath of fresh and authoritative air in the dermatological community. His contribution begins with essential background information on natural and artificial radiation, and moves to consider the effect of solar radiation on normal skin, and to the photosensitive disorders and the mechanisms thought to underly them. The important area of photosensitive drug reactions is covered particularly well and an excellent and comprehensive account of general phototherapy and photochemotherapy concludes his contribution.

The section on photosensitive drug reactions and their mechanisms could be read with advantage by all those involved in the prescription of the many potential photosensitisers, and the section on the value and side effects of photochemotherapy should be required reading for all those who currently operate 'PUVA' services. The section devoted to histological changes seen in UV exposed normal skin will obviously be of value and interest to diagnostic pathologists.

The section on lasers is also well handled by Dr John Cotterill, who is a Consultant Dermatologist at Leeds General Infirmary. It is divided mainly into two sections, one 